Portland State University

PDXScholar

1977

\title{
A Concept Acquisition Project Comparing Receptive and Expressive Programs
}

Carol Paulson Carpenter

Portland State University

Follow this and additional works at: https://pdxscholar.library.pdx.edu/open_access_etds

Part of the Speech Pathology and Audiology Commons

Let us know how access to this document benefits you.

\section{Recommended Citation}

Carpenter, Carol Paulson, "A Concept Acquisition Project Comparing Receptive and Expressive Programs" (1977). Dissertations and Theses. Paper 1220.

https://doi.org/10.15760/etd.1219

This Thesis is brought to you for free and open access. It has been accepted for inclusion in Dissertations and Theses by an authorized administrator of PDXScholar. Please contact us if we can make this document more accessible: pdxscholar@pdx.edu. 
THIS IS A CLINICAL PROJECT,

NOT A THESIS.

A CONCEPT ACQUISITION PROJECT COMPARING

RECEPTIVE AND EXPRESSIVE PROGRAMS

by

CAROL PAULSON CARPENTER

A clinical research project submitted in partial

fulfillment of the requirements for the degree of

\section{MASTER OF SCIENCE IN SPEECH COMMUNICATION \\ with an emphąsis in \\ SPEECH PATHOLOGY/AUDIOLOGY}

Portland State University

1977 


\section{ACKNOWLEDGMENTS}

There are a number of people who were directly, as well as indirectly, involved in this clinical project and were special to me in so many ways.

Mary Gordon, as my clinical project director, provided me with great guidance and support throughout the project in its planning, administrating, completing, and recording significant events and information. Her personable approach, particularly, was most appreciated. Mary has been instrumental in stimulating my academic, professional, and personal interest and growth in the field of speech pathology. Committee members Joan McMahon and Colin Dunkheld, through their knowledgeable and non-threatening input, encouraged me to "think things through" in a very positive manner, which I deeply appreciate.

The girls involved in this comparison study and their parents were very cooperative and helpful in making this project meaningful.

Finally, the emotionai interest of my family and friends was endless. My parents, sister, and friends 1istened supportively through the varions phases of this project and offered their encouragement at al1 times. My husband, John, especially experienced this project with me on ail levels. His patience, sensitivity, and sense of humor were consistent and enlightening.

Thank you all so much!! 
TABLE OF CONTENTS

PAGE

ACKNOWLEDGMENTS ...................... . . . . ii LIST OF TABLES ..................... . . . v

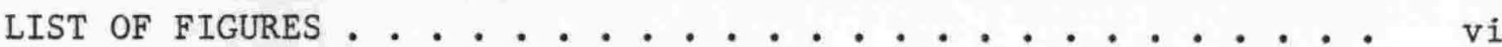
CHAPTER

I INTRODUCTION ................. 1

Statement of Purpose ........... 2

II REVIEW OF THE LITERATURE .............. 3

Concept Development............ 3

Comprehension versus Production......... 11

Selecting a Teaching Strategy . . . . . . . 16

III PROJECT DESIGN . . . . . . . . . . . . 20

Client Selection ................ 20

Procedures ................ 20

Evaluation .................. 24

IV RESULTS AND DISCUSSION . . . . . . . . . 25

Results................... 25

Discussion ................ 29

V SUMMARY AND CLINICAL IMPLICATIONS . . . . . . . . 32

Summary . . . . . . . . . . . 32

Clinical and Research Implications . . . . . 33 
SELECTED BIBLIOGRAPHY . . . . . . . . . . . . . 35 APPENDICES .................................... 38

A COLLINS AND CUNNINGHAM'S (1976) 7 STEPS . . . . . 38

B BOEHM TEST OF BASIC CONCEPTS, FORM A . . . . . . 40

C PERCENT PASSING, BOEHM TEST OF BASIC CONCEPTS, FORM A. 41

D INDIVIDUALIZED PRE- AND POST-TESTS FOR CLIENTS A AND B. 42

E DELIVERY SYSTEM FOR CLIENT A . . . . . . . . 43

F DELIVERY SYSTEM FOR CLIENT B ............ 49

G BOEHM TEST OF BASIC CONCEPTS . . . . . . . . 54

H INDIVIDUAL PROGRAM RESUltS ........... 56 


\section{LIST OF TABLES}

TABLE

PAGE

I PERCENTAGE OF SEMANTICALLY CORRECT RESPONSES . . . . . 7

II PERCENTAGE OF RESPONSES ACCOUNTED FOR BY USE OF

ORDERED RULES 1 AND 2 . . . . . . . . . . . . 8

III CLIENT SCORES ON LANGUAGE TESTS . . . . . . . . . . 21

IV COMPARED PROGRAM RESULTS . . . . . . . . . . 29 


\section{LIST OF FIGURES}

1 Precriterion trials (PCT) and precriterion errors

(PCE) in the acquisition of positive and

negative CVCs.............. 10

2 Expressive pre- and post-tests 1 and 2 results for

client A . . . . . . . . . . . . .

3 Receptive pre- and post-tests 1 and 2 results for client A..................

4 Expressive pre- and post-tests 1 and 2 for

client B................

5 Receptive pre- and post-tests 1 and 2 for 


\section{CHAPTER I}

\section{INTRODUCTION}

Surveys conducted during the last forty years have shown a growing recognition of the number of individuals with language deficits. In a recent survey by the American Speech and Hearing Association Committee on Language (Stark, 1971), speech pathologists indicated a large proportion of their case loads consists of children with language problems. Of the total sample, 36 percent reported more than 50 percent of their case loads was comprised primarily of language impaired.

Since language case loads are increasing, it becomes necessary to investigate current teaching strategies, as well as to review theories of language development. Information available raises questions and controversy as to how language develops. Evidence (Fraser, Bellugi, and Brown, 1963) suggests language comprehension normally precedes language production. Speaking seems to be more complex than comprehension in that speech production appears to be a recall function; whereas, speech comprehension implies a recognition function (Winitz, 1973). Winitz (1973) found many clinicians begin language instruction with production, although the results of naturalistic studies and investigations of second language learning suggest language training should begin with comprehension. On the other hand, even though they acknowledge that expression develops in a frequently observed sequence in young children and that reception precedes production, Gray and Ryan 
(1973) contended this sequence is not compulsory for development nor mandatory for instructional purposes. Further, they believe that so long as children are capable of perceiving and processing verbal stimuli (their only prerequisite to language training), then it is not necessary to build an extensive receptive language repertoire, using a non-verbal response, before teaching expressive language. In other words, the process of teaching expressive language results in teaching receptive language also. A question then arises as to which approach to management (i.e., receptive, expressive, or a combination of both) is more appropriate with a child who demonstrates a delay in language.

\section{Statement of Purpose}

The purpose of this project was to measure and compare the language concept growth of two clients who utilized different response modes; client A utilized the expressive mode and client B utilized the receptive mode. A systematic management program was administered to each client for eighteen sessions (see Appendix A). The specific questions posed were:

1. Did both clients demonstrate the ability to verbalize concepts on the post-tests of the individualized programs?

2. Did client A learn more concepts in eighteen sessions than client $B$ as measured by the post-tests of the individualized programs and the Boehm Test of Basic Concepts?

3. Did both clients tend to learn each concept in a similar number of trials? 


\section{REVIEW OF THE LITERATURE}

\section{Concept Development}

Language does not develop in a vacuum; it develops as a function of representing thoughts, percepts, and feelings (Clark, 1974). It is a communicative system, designed to convey to another person what one might think, feel, or see. For this reason language is linked to the conceptual framework that underlies it. A child brings perceptualcognitive skills to the complex task of learning what language means and what the relationship is between his experience and the words used to convey it to another person. Language also constitutes input to such a cognitive, interpretive system; therefore, it is assumed that the semantics of a language is so similar with the cognitive, interpretive system as to allow association between the two (Clark, 1974). This association appears to be a basic requirement, given that language is used to talk about all kinds of input into this interpretive system. The study of children's language acquisition has long been of interest to both psychologists and linguists (Blumenthal, 1970; and Hopper and Naremore, 1973) and in the early sixties, Chomsky's (1965) work in linguistics provided new incentive for research on this topic. Until recently, most of this research has been concerned primarily with the acquisition of syntax, i.e., grammatical markers such as articles and inflections, word order, and the underlying grammatical relations 
such as "subject" and "verb" of the sentence phrase (McNeil1, 1970). This seems to have led investigators to overlook, or more probably, assume the existence of the cognitive phenomena that underlie language. The child who is learning language, though, has to find out exactly what aspects of his experiences can be represented in words at a point in which he still knows very little about the language he is learning and at a stage in which his experiences and knowledge are still rather limited compared to the adult's.

Recently, Slobin (1973) proposed the child will first learn those aspects of language that are within the scope of his current cognitive development, so that as the child develops cognitively, he will gradually learn to use more complex linguistic formulations. In other words, cognitive development provides the basis for language acquisition, and the order in which certain linguistic distinctions will be acquired can be predicted on the basis of the relative cognitive complexity.

Clark (1974) focused on the role played by the kinds of strategies and cognitive processes children bring to the task of acquiring language and, more specifically, the basic process of assigning meaning to words. By pointing out an appropriate exemplar of the category referred to, Clark (1974) stated that many words can be labeled or "defined." In other words, many times children learn some words from having a physical referent, e.g., having an adult point out an object and label it. She warned, however, these demonstrable or ostensive definitions do not provide one with much information about the set of critical features of the category named (Clark, 1973). The child has 
to decide which is the relevant factor of the many features he can see. Clark (1974) speculated that if the child decides everything is relevant, he might, for example, treat "doggie" as a proper name, unique to that one animal; in other words, the child would have set up a more exclusive category than the adult one. According to Clark (1973), the data available suggest the child initially selects only one or two features as critical and gradually adds the other features used by the adult until meaning for the word eventually matches the adult meaning.

It has been noted that these generalizations (Hopper and Naremore, 1973) or overextensions (Clark, 1973), e.g., calling all four-legged animals dogs, are common in the early stages of language acquisition. The child begins with certain hypotheses about what a "new" word might mean. Also it has been shown that a child's hypothesis may differ considerably from the adult meaning and, as a result, the child makes consistent errors in his interpretations (Hopper and Naremore, 1973). These errors can be accounted for by the cognitive strategies that are used by the child prior to the acquisition of semantic knowledge (01son, 1970). The strategies used with respect to both nonrelational words like "doggie" and relational words like "in" or "under" appear to be derived primarily from the child's prior knowledge of the "way things are" in the world around him (Clark, 1974).

Many words in language, however, do not have tangible referents because instead of naming objects, they name relations between objects or between events. Other words label properties that are variable and tend to be assessed relative to some standard which itself also may vary, e.g., "under," "after," "in front of," "big," and "wide." Such 
words do not offer the possibility of simply pointing in order to identify the referent of the word, although in a few cases the child might try to demonstrate the meaning through his actions (Clark, 1973). Nonetheless, during the course of learning language the child manages to learn the meanings of words for tangible referents and words for relations.

Recently, Clark (1974) studied the acquisition of relational terms, specifically locative terms, e.g., "in," "on," and "under," and certain dimensional adjective pairs, e.g., "big," "sma11," "tall," and "short," by children aged 1.6 to 5.0. She found that the order of acquisition of the three terms "in," "on," and "under" seemed to be the result of an interaction between the child's initial hypothesis about what the words mean and what these words actually mean (adult definition). In other words, children internally formulate rules which may or may not agree with the adult meaning. When the children's responses were scored according to adult criteria for semantically appropriate responses, the majority of children over 3.0 used all three prepositions correctly. However, there were significant differences among the three younger groups because of the general increase in percentage correct with age. Furthermore, each preposition produced a different pattern of improvement (see Table I).

It would appear that children acquire certain ordered rules based upon their perception of what Clark (1974) refers to as normal or canonical spatial relations. Clark describes these rules as follows:

Rule 1: If the reference point (RP) is a container, $x$ is inside $i t$. 
Rule 2: If RP has a horizontal surface, $x$ is on it.

TABLE I

PERCENTAGE OF SEMANTICALLY CORRECT RESPONSES*

\begin{tabular}{|c|c|c|c|c|c|c|}
\hline Group & $\mathrm{N}$ & $\begin{array}{l}\text { Mean Age } \\
\text { Yrs.: Mos. }\end{array}$ & $\begin{array}{l}\% \\
\text { In }\end{array}$ & $\begin{array}{c}\text { Ins } \\
\text { Corre } \\
\text { On }\end{array}$ & $\begin{array}{l}\text { ructior } \\
\text { Respo } \\
\text { Under }\end{array}$ & $\begin{array}{l}\text { ses } \\
\text { Mean }\end{array}$ \\
\hline I & 10 & $1: 9$ & 94 & 61 & 4 & 53 \\
\hline II & 10 & $2: 3$ & 98 & 72 & 57 & 76 \\
\hline III & 10 & $2: 9$ & 96 & 80 & 98 & 91 \\
\hline
\end{tabular}

*Each percentage based on 80 data points. Table based on Clark (1973).

In the case of the term learned the earliest, "in," the child's strategy coincided with the adult meaning. Thus, the child follows rule 1 (if the $\mathrm{RP}$ is a container, $\mathrm{x}$ is inside it). With "on," the child is sometimes right and sometimes wrong if he simply follows rules 1 and 2 (if the RP has a horizontal surface, $x$ is on $i t$ ). He, therefore, has to adjust his use of such rules and learn when not to apply them. The same logic has to be followed for "under," but in this instance neither rule will produce a semantically correct response and so the child has to learn to disregard these strategies altogether (Clark, 1973). These rules suggest an alternative approach to the comprehension data reported in Table I. Clark (1974) stated that it is quite possible that very young children do not understand "in," "on," and "under." Therefore, more of their data should be accounted for by the use of rules 1 and 2 than by adult semantics criteria. The data accounted for by the strategies represented as rules 1 and 2 are shown 
in Table II.

TABLE II

PERCENTAGE OF RESPONSES ACCOUNTED FOR BY

USE OF ORDERED RULES 1 AND $2 *$

\begin{tabular}{rrrrr}
\hline & \multicolumn{5}{c}{ Instruction } \\
\hline Group & In & On & Under & Mean \\
\hline I & 94 & 79 & 96 & 89 \\
II & 95 & 72 & 43 & 69 \\
III & 96 & 62 & 3 & 54 \\
\hline
\end{tabular}

*Each percentage based on 80 data points. Table based on Clark (1973).

It seems that more "rules" are formulated as the child becomes older so that his hypotheses more closely match the adult meaning. Thus the child begins by depending simply on his strategies, but these give way to semantic knowledge as the child becomes older. Clark's data also seem to provide further corroboration of Slobin's (1973) hypothesis that relative cognitive complexity is the basic determinant of order of acquisition. This also enables one to make predictions about order of acquisition across languages, as well as within a particular language.

The notion that children initially set up hypotheses about what words mean and then derive strategies for interpretation is also compatible with some work that has attempted to account for the asymmetry observed in the acquisition of positive dimensional adjectives, e.g., "big," "tall," "wide," and their negative counterparts, e.g., "small," "short," and "narrow." Children acquiring their first language 
consistently learn to use and understand positive terms before negative ones (Greenberg, 1966). Greenberg (1966) further noted that dimensional adjective pairs such as "high-low" or "long-short" are not used proportionally in frequency of usage.

Klatzky, Clark, and Macken (1973) designed a study which attempted to differentiate between an adult usage/frequency explanation for the asymmetry and an explanation based on a conceptual asymmetry. Young children were given a concept learning task in which nonsense syllables (CVCs) replaced the English words for both the positive and the negative poles of four dimensions: size, height, length, and thickness. The learning data for the CVCs showed that the syllables for the positive and of each of the four dimensions required significantly fewer trials to reach criterion and produced significantly fewer errors during learning. These data are shown in Figure 1.

Similarly, Donaldson and Wales (1970) reported that children aged 3 years, 6 months, to 5 years rarely use negative adjectives in their spontaneous speech to describe the relations between objects that differ on various dimensions. Furthermore, Palermo (1973) also found that children consistently appear to understand positive terms before negative ones during acquisition.

Attainment of concepts such as those described above appear to be universal (Lenneberg and Lenneberg, 1975). Lenneberg and Lenneberg (1975) noted that the speed of their complete form may differ according to gross cultural differences, but the cognitive operations concerned are essentially the same. According to Lenneberg and Lenneberg (1975), the knowledge acquired is built up actively by generalizing and 
abstracting from actions; it is not the result of more and more faithful copying of the environment.

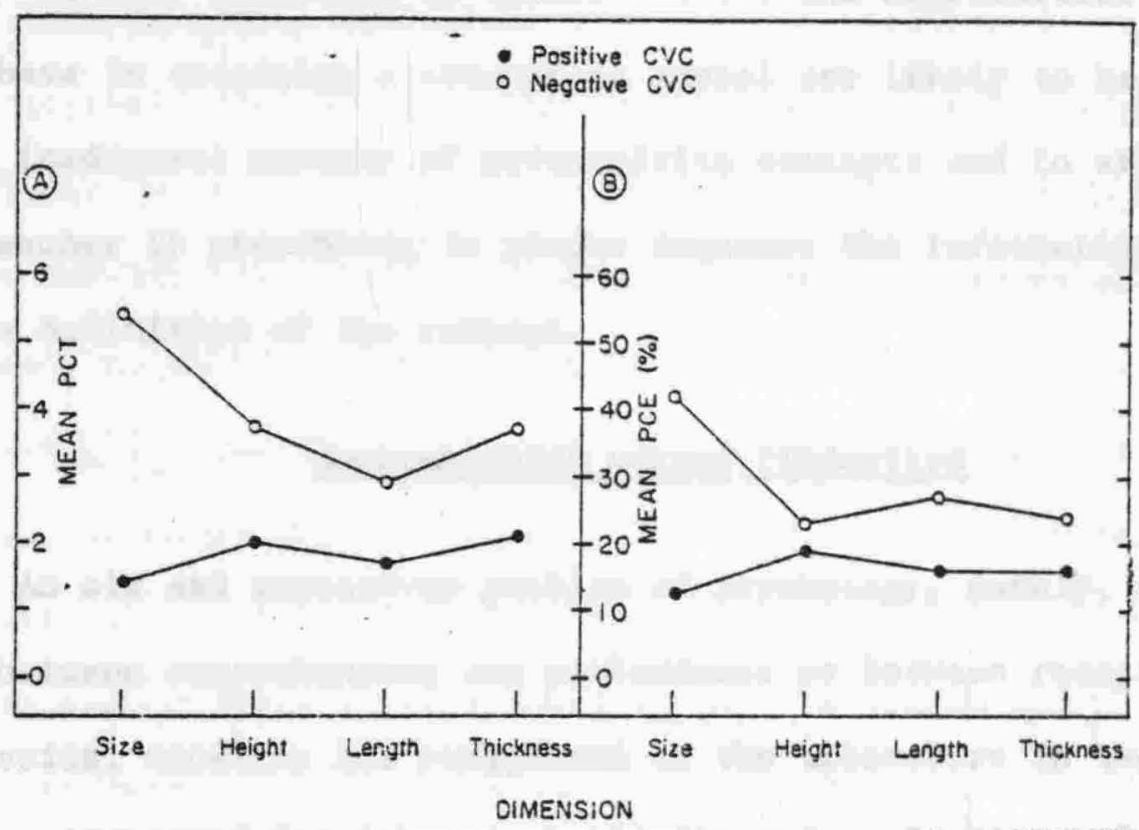

Figure 1. Precriterion trials (PCT) and precriterion errors (PCE) in the acquisition of positive and negative CVCs. Based on Klatzky, Clark, and Macken (1973).

Carroll (1967) cautioned that research should be carefully interpreted and he noted that concept learning in the laboratory (such as those concepts described earlier) does differ considerably from concept learning in schools. He described five major differences:

1. A new concept learned in school is usually a genuinely "new" concept rather than an artificial combination of familiar attributes.

2. Concepts learned in school often depend upon a network of prerelated or prerequisite concepts.

3. Many of the more difficult concepts of school learning are of a relational rather than a conjunctive character; they deal with relations among attributes rather than their combined presence or absence. 
4. Problems of paired-associated memory are added to those of concept learning itself.

5. School concept learning appears inductive.

In conclusion, according to Carroll (1967) the difficulties that children have in attaining a concept in school are likely to be due to their inadequate mastery of prerequisite concepts and to errors made by the teacher in presenting in proper sequence the information intrinsic to the definition of the concept.

\section{Comprehension versus Production}

An old and unresolved problem of psychology, namely, the difference between comprehension and performance or between reception and expression, recently has reappeared in the literature in the form of the developmental lag between perceiving and performing. It has long been known that young children make visual perceptual distinctions, such as recognizing a square, long before they incorporate these distinctions into their copying behavior (Piaget and Inhelder, 1965). Similarly, children recognize and understand words and sentences long before they generate them (Fraser, Bellugi, and Brown, 1963).

To account for these and other similar observations, Maccoby and Bee (1965) advanced and evaluated several hypotheses. The first was that the child may be using his own idiosyncratic set of cues as a guide to his recognition or production of a word or a visual form. The cues may be unambiguous enough so that what the child accepted as a word or a figure is not accepted by an adult. If this is the case, children should recognize their own distorted productions better than those of other children. Maccoby and Bee (1965) presented evidence 
that children do not, in fact, discriminate their own copied forms better than those of other children; however, they did not reject the possibility that children may use these idiosyncratic cues in other areas such as speech recognition.

Another alternative hypothesis presented by Maccoby and Bee (1965) was the child simply lacks the motor skills to draw what he sees. Piaget and Inhelder (1965) disputed this, for they found that the children were no better at assembling components of a form than they were at drawing it; yet the two obviously require quite different motor skills. Although Maccoby and Bee (1965) did implicate motor skills somewhat, they concluded that motor skill is not a sufficient condition because the children could recognize the form before they could copy it by either assembling its parts or drawing it.

The final hypothesis, and the one in which Maccoby and Bee (1965) placed their greatest reliance, is the "number of attributes" hypothesis. They stated "to reproduce a figure, the subject must make use of more attributes of the model than are required for most perceptual discriminations of this same model from other figures." Graham, Berman, and Ernhart (1965) found in their study of children's copying of forms that the number of attributes correctly reproduced increased in a linear fashion with age.

Piaget and Inhelder's (1965) account of the difference between recognition and reproduction of a form revolved about the concept of "representation." To recognize a square, a child must have a perceptual schema which has been constructed on the basis of repeated encounters with squares. This schema may be activated by an appropriate 
stimulus in the visual field. To draw a square, however, the child has to be able to consider or to represent the square in its absence. Thus, the lag between perceiving and performing is not to be filled simply by more or better perceptions, but by the postulation of a new level of representational thought that arises from perceptual and motor activity.

Although some of these explanations have not been explicitly extended to young children learning language, they do contribute to an exploration of the developmental relationship among understanding, talking, and thinking. It is also possible that the copying of a form is not the same as that for generating a word or sentence. It appears that language explanations have generally taken four different routes. First, there are some who believe that children acquire two grammars, one for production and one for comprehension, and that acquisition is faster for the comprehensive grammar. According to Bloom (1974), expression and comprehension are clearly different behaviors and seem to involve more than a temporal (time) relation in the course of their development. Bloom proposed the relationship between them is not one of mutual dependence, but of different underlying processes. Ingram (1974) stated that comprehension does precede production. He argued that the relationship, as it has been traditionally understood, is a unidirectional one in which some comprehension of a specific grammatical form or construction must occur before (or at the same time as) it is produced. He also observed that some children appear to say everything they know; others, much less so. In the latter case, the child's comprehension development appears to be ahead of production. 
This is often true of children with language disorders (Ingram, 1974). Guess (1969) found in training subjects in receptive behavior that productive speech did not follow automatically from a demonstration of receptive ability.

A second hypothesis is that comprehension can make use of contextual information not available for production (McNeill, 1970). Thus children appear to understand passive sentences before they produce them, because they are helped by context; typically, only one meaning is plausible. This explanation, according to McNeill (1970), assumes that production and comprehension do not differ. In an experiment by Fraser, Bellugi, and Brown (1963), however, a gap appeared between production and comprehension, even when the contextual support was the same for both.

Thirdly, it has been suggested that the load on short-term memory is greater for production than for comprehension, so a child is likely to forget a form in production, although he could remember it in comprehension (McNeill, 1970).

In regard to the study of verbal memory, Mandler (1967) made a distinction between "availability" and "accessibility" in memory. The important items may be stored, that is, available, but they may be organized, or disorganized, in such a way that they are not accessible to recall.

Bloom (1974) viewed the memory load for saying a word or sentence as presumably greater than for understanding, inasmuch as the individual needs to recall the necessary words and their connections to say them; but these linguistic facts are immediately available to him when 
he hears them spoken by someone else. The child can experience a sentence as more or less independent of its parts, but saying sentences involves bringing together the elements to form a whole. In recognizing a word or sentence, a child relates what he hears to existing perceptual schemas, but saying the word or sentence involves reconstructing an intervening representation in the form of "symbolic image" (Piaget and Inhelder, 1965).

It is not clear how representational images relate to either acoustic signals that the child hears or the speech that he himself produces (Bloom, 1974). Bloom (1974) stated that reception and expression seem to involve the reconstruction of existing schemas, but perhaps, at different levels of complexity. While this theory explains the gap between production and comprehension, it does not explain what causes such a difference in demands on memory.

The final hypothesis is that the slowness of child speech causes the difference in receptive and expressive development (McNeil1, 1968). McNeill (1968) noted that for an adult very slow speech leads to confusion. At a rate of one word every three or four seconds, the structure of a sentence will collapse as it is being uttered (there must be no rehearsal for this to occur). According to McNeill (1968), a similar limitation exists for young children. Forms would then of ten be comprehended, but not produced, because in comprehending children typically listen to speech delivered at a rate greater than their own. This hypothesis, however, is incorrect. While comprehension deteriorates at slow speaking rates, McNeill found it is best at children's own relatively slow rate. The gap between production and comprehension evi- 
dently does not depend on children's slow rate of speech as they comprehend that rate best.

At the present time there is not enough information to explain the relationship between speaking and understanding in language development. McNeill (1970) concluded the lag between reception and expression may be noted because "children probably add new information to their linguistic competence mainly by comprehending speech." At best, the research that has been conducted is contradictory and inconclusive. However, it is important to emphasize the relationship between comprehension and production is probably never a static one, but rather, shifts and varies according to the experience of the individual child and his developing linguistic and cognitive abilities.

\section{Selecting a Teaching Strategy}

Some children do not develop language concepts normally and are enrolled in language management programs to aid them in concept development. Teaching strategies for these children vary according to clinician preference and time, as well as the needs of the child. Some clinicians prefer a "games" approach; some, a drill approach; while others prefer a creative dramatics approach. More recently a behavior modification or programmed conditioning approach has been employed and appears to be demonstrating favorable, as well as observable, results. During a recent workshop, Collins and Cunningham (1976) asked clinicians to describe their problems in planning and executing clinical activities. The following were noted:

1. Objectives for treatment are frequently written on a day-to-day basis, or not at all. 
2. The clinician may monopolize the treatment time.

3. The client may have a low rate of correct responses per session.

4. The clinician may not be able to describe his procedures to others.

5. The clinician may have difficulty staying on task.

6. Testing frequently does not relate to treatment.

7. The clinician may not be able to describe a hierarchy of events leading to mastery of a skill.

8. The client may not know where he is in relation to treatment goals.

Collins and Cunningham (1976) contended a programmed approach to treatment of speech and language disorders will alleviate the above problems, as well as produce a high rate of correct responses and lead to earlier dismissal from treatment.

If the speech pathologist wishes to be prepared to offer programmed treatment for all speech and language target behaviors, she needs a relatively simple, fast system with which to create such programs. Collins and Cunningham offer such a system which is described in Appendix A.

Gray and Ryan (1973) developed and administered programmed expressive and receptive language programs to kindergarten and first grade children, one group with normal language development (control group) and one group lacking basic linguistic competence (sample group). They found the programming resulted in gains in both receptive and expressive ability, with proportionally greater gains in expressive performance. The following was noted with the sample group: 1) initially, reception was greater than expression; and 2) for every unit 
increase in expression, there was a correspondingly smaller increase in reception. On the other hand, although the control group displayed initial differences between expression and reception in the same direction, these differences were not as large as the sample group. Also, there was nearly a one to one correspondence in change in expression and reception (Gray and Ryan, 1973).

From their research Gray and Ryan (1971) created the Monterey Language Program. It is a syntax program which basically utilizes an expressive mode of client responding. This programmed approach to syntax acquisition was based on the assumption that a child will learn the syntactical features of language expressively, as well as receptively, by the clinician's auditory model alone. With the exception of program 1, the client's responses are all in the expressive mode. This program utilizes group and individual instruction.

Another widely used commercial language program is Distar Language I and II (Engelmann, Osborn, and Engelmann, 1969). It incorporates both expressive and receptive modes of client responding. This program takes a multidimensional approach to the acquisition of syntax, concept development, categorization, and auditory perceptual skills, i.e., auditory memory and sequencing. It is designed for group instruction.

The Peabody Language Development Kits (Dunn and Smith, 1966) are also popular among classroom teachers, speech clinicians, special educators, and language developmentalists for overall language skills. These are language programs designed to stimulate reception, expression, and conceptualization skills in children. Vocal, motor, sight, hearing, 
and touch are the modalities utilized in this program. These programs are best utilized in a group setting.

Research has not conclusively shown whether receptive knowledge of concepts results in expression of those concepts or whether the expression of concepts results in receptive understanding of those concepts. Further, language programs in use frequently utilize an expressive mode of client responding exclusively or a combination of receptive and expressive client responding. Readily available language programs tend to be syntactically oriented or combine syntax with other language skills in one program. A need then arises to study receptive versus expressive client responding in the area of concept acquisitional development. 
CHAPTER III

\section{PROJECT DESIGN}

\section{Client Selection}

The clients for this clinical project were two children, aged 5.8 and 5.5, from the Reynolds School District 非, Troutdale, Oregon. They were females from middle socioeconomic level Caucasian families. Both clients were from monolingual homes and neither demonstrated any known organic pathology. Both clients displayed normal bilateral hearing defined as no loss greater than $20 \mathrm{~dB}$ ISO for the frequencies of 500 , 1000,2000 , and $4000 \mathrm{~Hz}$. Neither previously had received speech and/or language intervention.

Prior to participation in the project, both clients showed similar below age level language profiles according to the Peabody Picture Vocabulary Test, form A (Dunn, 1965); the Boehm Test of Basic Concepts (Boehm), form A (Boehm, 1967); and the Utah Language Development Test (Mecham, Jex, and Jones, 1969). Table III illustrates similarities between their below age level language performances. These language evaluation instruments were administered by this clinician, a Master's candidate in Speech Pathology.

\section{Procedures}

Six of the concepts chosen for remediation were those which both clients missed on the Boehm, form A (Appendix B). Two additional con- 
cepts missed by client A on the Boehm, form A, were presented to client A only. Both clients attended the same number of clinical management sessions. According to the Boehm normative data, these concepts are mastered by 60 percent or more of the sample population of middle socioeconomic level kindergarten children (see Appendix C). The following concepts were chosen for remediation for both clients: "behind," "over," "center," "between," "after," and "side." Additionally, the concepts of "away from" and "second" were chosen for client A for remediation.

TABLE III

CLIENT SCORES ON LANGUAGE TESTS

Test

Client A Client B

Peabody Picture Vocabulary Test Form A

Raw Score:

Mental Age:

45

4.5

48

4.10

Boehm Test of Basic Concepts

Form A

$\begin{array}{lll}\text { Total Correct: } & 28 & 30 \\ \text { Percentile: } & 20 \text { th } & 25 \text { th }\end{array}$

Utah Language Development Test

$\begin{array}{crr}\text { Raw Score: } & 26 & 25 \\ \text { Language Age Equivalent: } & 5.3 & 5.0\end{array}$

In addition to providing data for selection of concepts, the Boehm, form A, served as a pre-test. Receptive and expressive program pre-tests were also administered to each client prior to participation in the individualized programs (see Appendix D). 
The Collins and Cunningham (1976) 7-step individualized program framework was then utilized with each client (see Appendix A). Client A was administered a concept program utilizing the expressive mode (i.e., client verbally named concepts) and client $B$ was administered a concept program utilizing the receptive mode (i.e., client placed objects in appropriate relationship to one another)..

Ten objects (horse, dog, helicopter, doll, truck, car, iron, duck, robot, airplane) were presented in random order to each client every session. Client $A^{\prime}$ 's expressive program consisted of six progressive steps to mastery for each of the eight concepts presented ("behind," "over," "center," "away from," "second," "between," "after," and "side"). Step 1 of client A's expressive program consisted of the following:

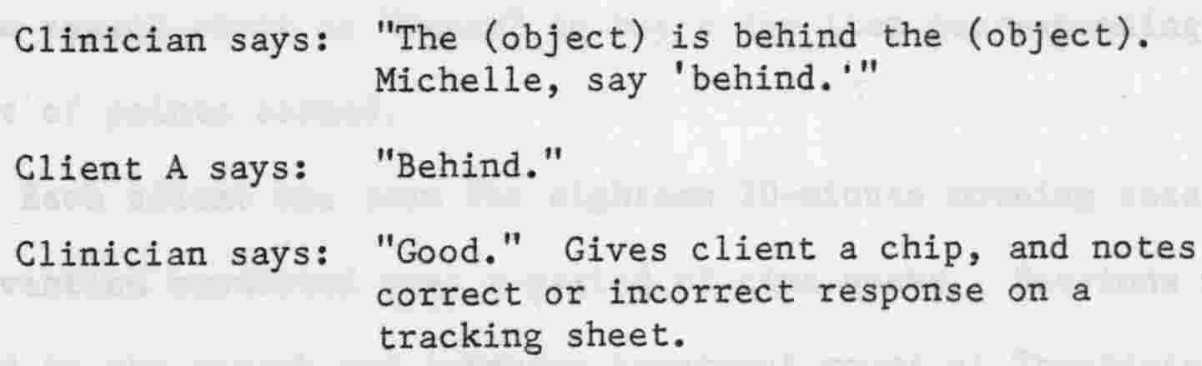

This sequence continued until client A responded correctly on ten consecutive trials. Steps $2,3,4,5,6$, etc., were then administered as criteria for movement as each step was met by client A. Appendix E illustrates client $A^{\prime}$ s complete program.

Client $B^{\prime}$ s receptive program consisted of five progressive steps to mastery for each of six concepts presented ("behind," "over," "center," "between," "after," and "side"). Step 1 of client B's receptive program consisted of the following: 


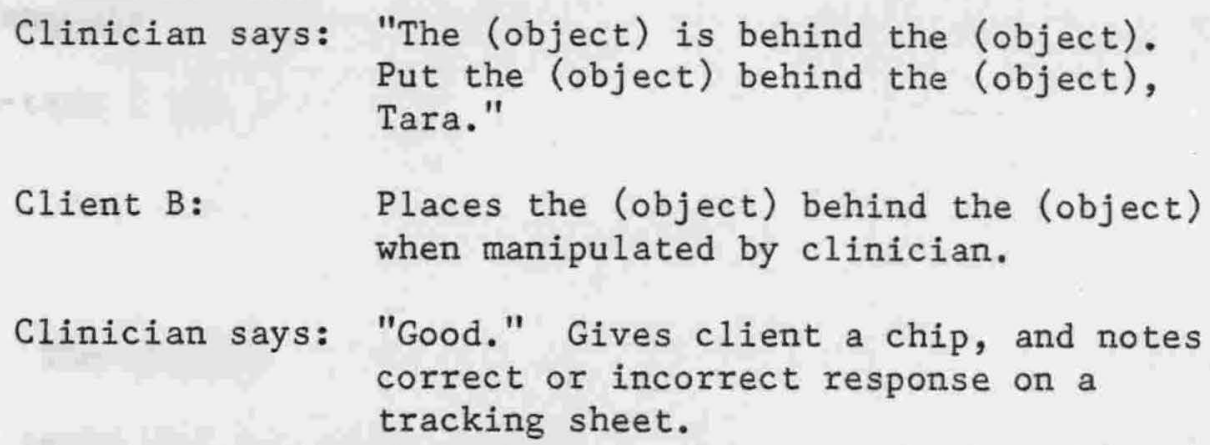

This sequence was continued until client B responded correctly on ten consecutive trials. Steps $2,3,4,5$, etc., were then administered as criteria for movement as each step was met by client B. Appendix F illustrates client $B^{\prime}$ 's complete program.

The token reinforcers (chips) earned by each client were counted by the client with the help of this clinician following each session and entered on a chart. These points in turn were used by each client in the speech store as "money" to buy a toy item corresponding to the number of points earned.

Each client was seen for eighteen 20-minute morning sessions of intervention conducted over a period of nine weeks. Sessions were conducted in the speech and language treatment rooms of Troutdale and Hartley Elementary Schools. Neither client's parents observed clinical management sessions.

Two post-test sessions followed the completion of each client's individualized concept program. The Boehm, form B, and the receptive and expressive program pre-tests were administered to both clients, as post-test 1 , one day following completion of the individualized program. Post-test session 2 consisted of the receptive and expressive program pre-tests only and was administered two weeks following post-test 1 . 
No language intervention took place during the 2-week period between post-test 1 and post-test 2 .

\section{Evaluation}

The changes in performances on the receptive and expressive program tests and the Boehm between pre- and post-tests 1 and between preand post-tests 2 were determined for each client. These changes were compared using percentages to answer the questions posed prior to initiation of this project. 
CHAPTER IV

RESULTS AND DISCUSSION

\section{$\underline{\text { Results }}$}

The questions posed prior to initiation of this project and relevant results are presented below. The first question was:

Did both clients demonstrate the ability to verbalize concepts on the post-tests of the individualized programs?

Both clients verbalized the concepts of "behind," "over," "center," "between," "after," and "side" on the post-tests of the individualized programs. Figures 2, 3, 4, and 5 illustrate their pre- and posttest performances for five trials for each concept. Both clients verbalized all concepts with 100 percent accuracy on post-test 1. Client A (expressive program) verbalized the concepts of "over," "center," "between," "after," "side," "away from," and "second" with 100 percent accuracy" and "behind" with 60 percent accuracy on post-test 2. Client B (receptive program) verbalized the concepts of "behind," "over," and "center" with 100 percent accuracy; "between" and "after" with 80 percent accuracy; and "side" with 60 percent accuracy on post-test 2 . Additional information is provided by examining the performances of the clients on the receptive pre- and post-tests. Client A learned the concepts of "behind," "over," "center," "away from," "second," "between," "after," and "side" receptively with 100 percent accuracy on post-test 1. All of these concepts were learned receptively with 100 

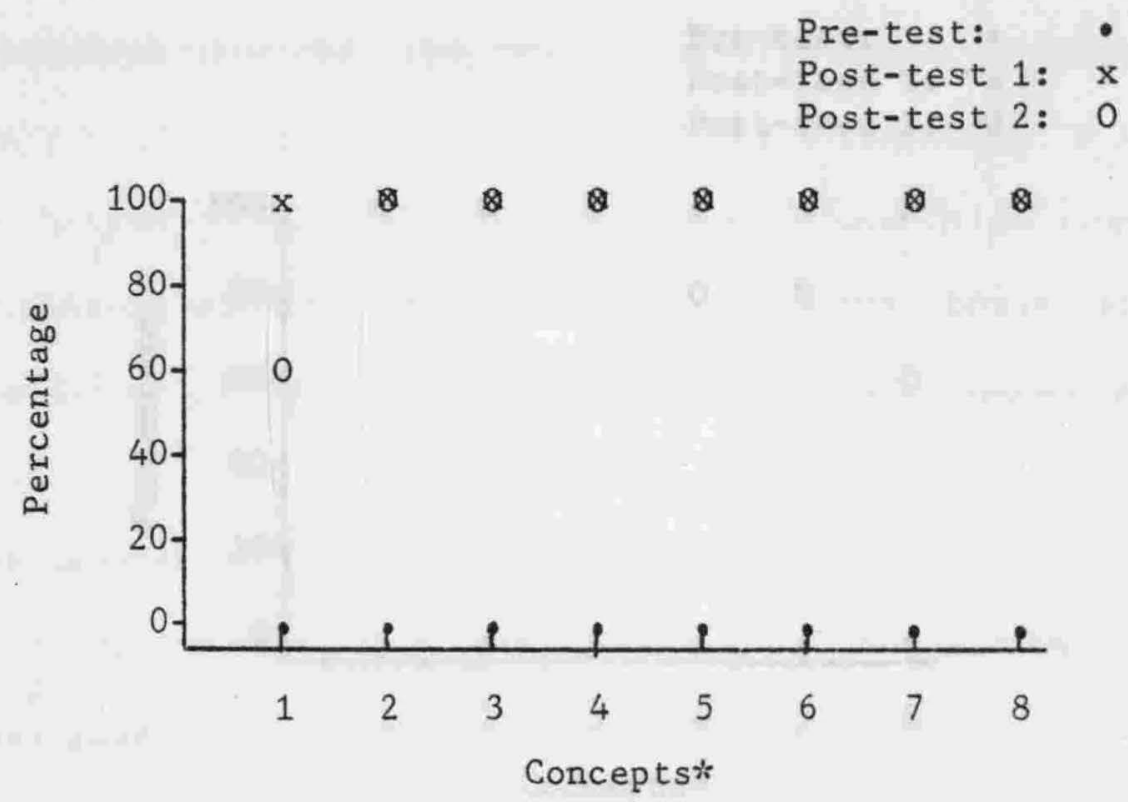

Figure 2. Expressive pre- and post-tests 1 and 2 results for client A. Five trials were presented on each concept.

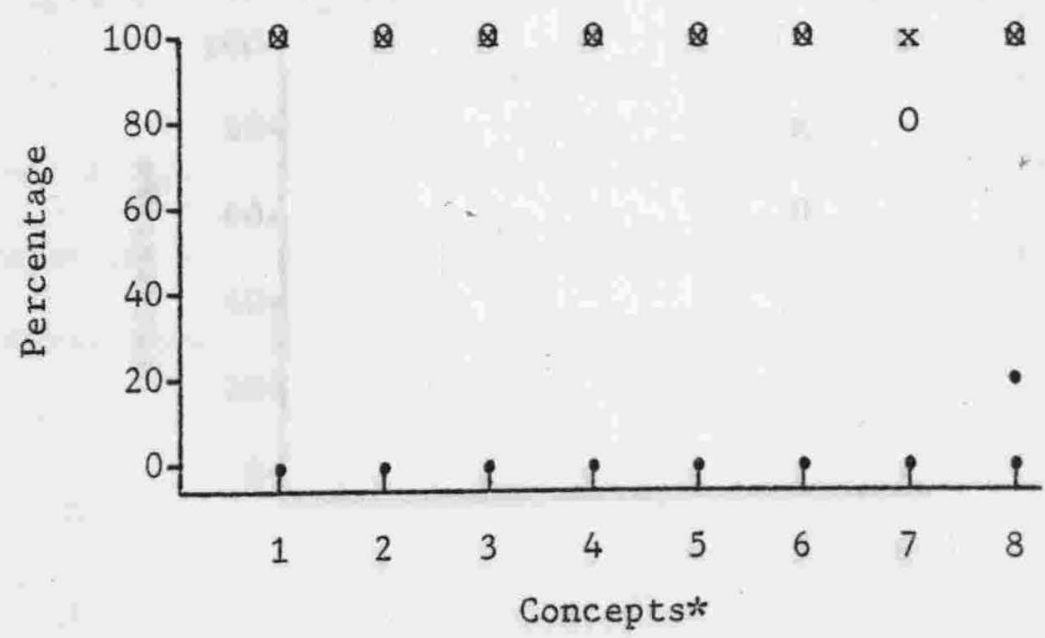

Figure 3. Receptive pre- and post-tests 1 and 2 results for client A. Five trials were presented on each concept.

*Concepts :

$\begin{array}{llll}1 & \text { Behind } & 5 & \text { Second } \\ 2 & \text { Over } & 6 & \text { Between } \\ 3 & \text { Center } & 7 & \text { After } \\ 4 & \text { Away from } & 8 & \text { Side }\end{array}$




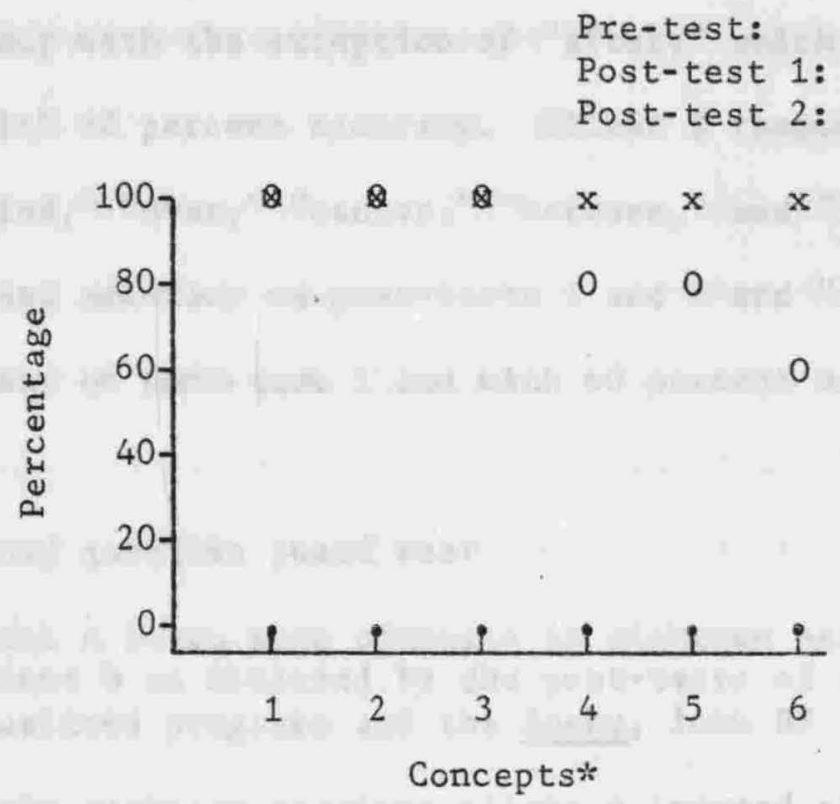

Figure 4. Expressive pre- and post-tests 1 and 2 for client B. Five trials were presented on each concept.

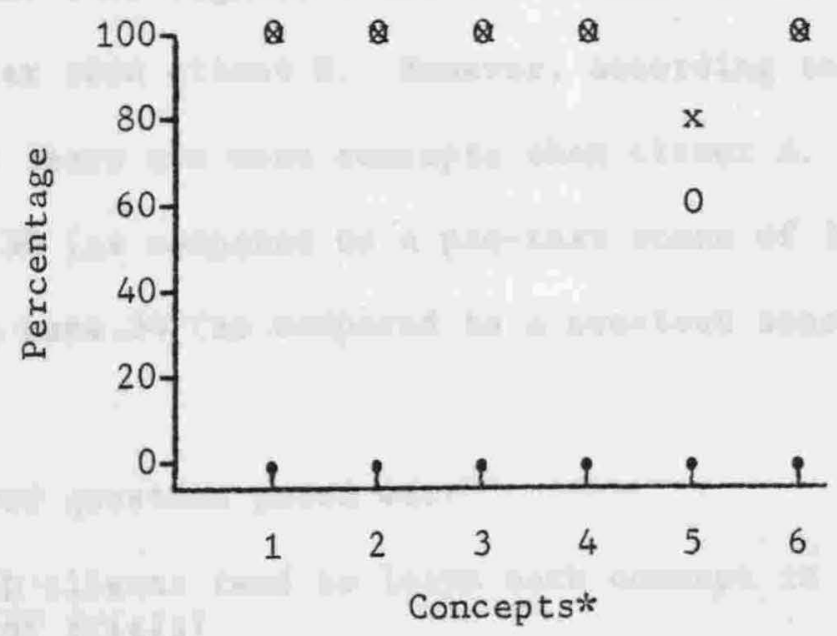

Figure 5. Receptive pre- and post-tests 1 and 2 for client B. Five trials were presented on each concept.

*Concepts :

1 Behind

2 Over

3 Center
4 Between

5 After

6 Side 
percent accuracy with the exception of "after," which was learned receptively with 60 percent accuracy. Client $B$ responded to the concepts of "behind," "over," "center," "between," and "side" receptively with 100 percent accuracy on post-tests 1 and 2 and "after" with 80 percent accuracy on post-test 1 and with 60 percent accuracy on posttest 2 .

The second question posed was:

Did client A learn more concepts in eighteen sessions than client $B$ as measured by the post-tests of the individualized programs and the Boehm, form B?

During the eighteen sessions client A learned eight concepts; whereas, client B learned six. Client A learned the additional concepts of "away from" and "second" expressively and receptively with 100 percent accuracy as demonstrated by post-tests 1 and 2 of the individualized programs (see Figures 2 and 3 ). Client A also met step-by-step criteria faster than client B. However, according to the Boehm, client B appeared to learn two more concepts than client A. Client B's total correct were 38 (as compared to a pre-test score of 30 ) and client $A^{\prime} s$ total correct were 34 (as compared to a pre-test score of 28) (see Appendix G).

The third question posed was:

Did both clients tend to learn each concept in a similar number of trials?

Each client did not learn each concept in a similar number of trials. The mean number of trials for client A to learn eight concepts was 158 , while the mean number of trials for client B to learn six concepts was 216. It is also interesting to note client A learned eight 
concepts in fewer trials (1261) than it took client B to learn six concepts (1299). Refer to Table IV and Appendix H for data illustrating the number of trials required for each client to learn the individual concepts. Table IV also illustrates that client A learned the concepts "behind," "center," and "side" in fewer trials than client B; however, client B learned the concepts "over," "between," and "after" in fewer trials than client A (see Appendix $H$ for specific number of trials).

TABLE IV

COMPARED PROGRAM RESULTS

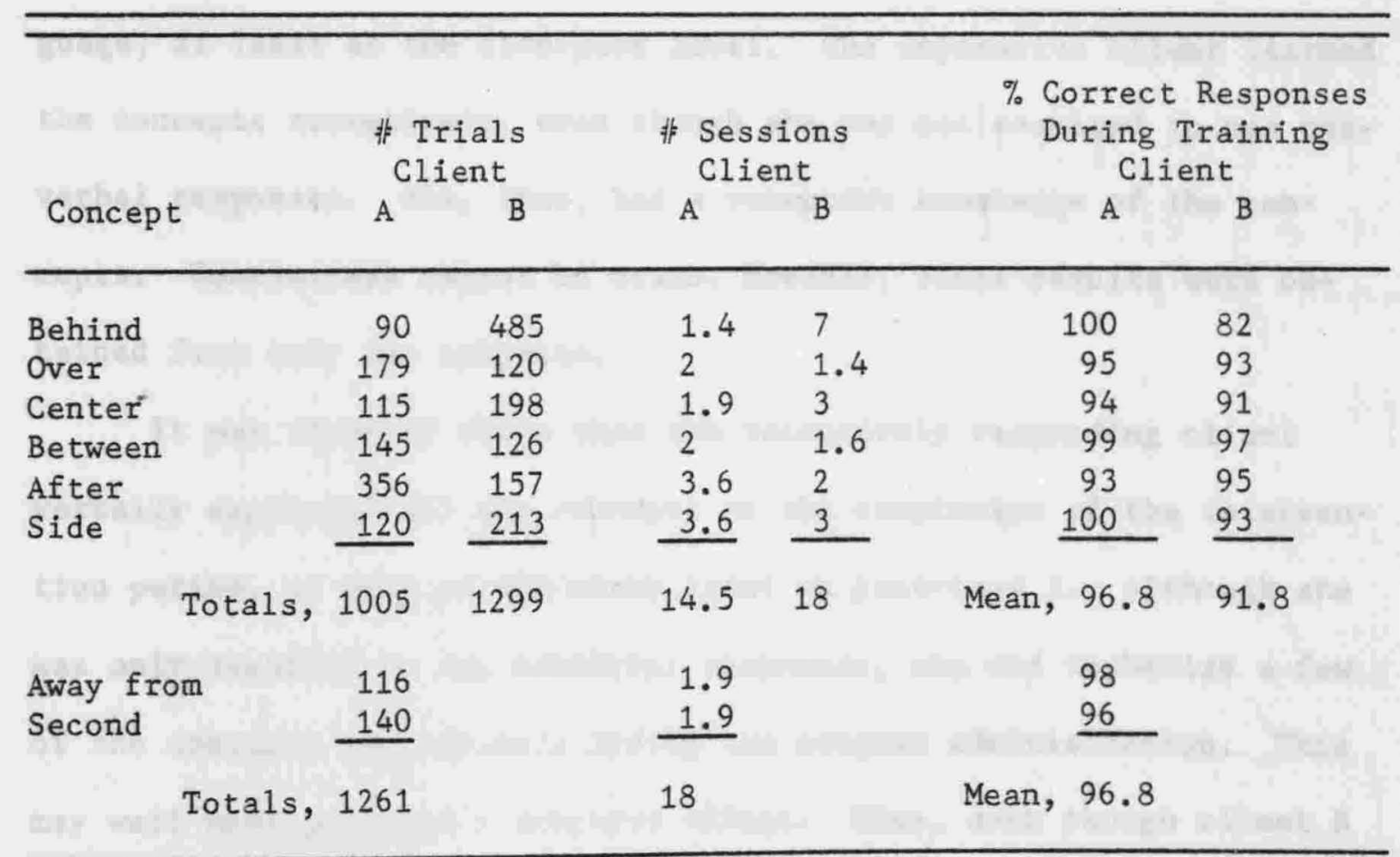

\section{Discussion}

It was noted above that client A (expressive) learned eight concepts in a fewer number of trials (1261) than client B (receptive) did for six concepts (1299). It would thus appear the expressive responding 
approach to remediation is a more efficient approach for the five-year level. The expressive client also retained these concepts both receptively and expressively with a higher accuracy rate than the receptive client as demonstrated by their performances two weeks following intervention on post-test 2 . In other words, maintenance appeared somewhat more successful with client A than client B. If this is a typical learning pattern, the expressive approach appears to be more effective. These results tend to support Gray and Ryan's (1973) contention that it is not necessary to build a receptive language repertoire through the use of nonverbal responding before teaching expressive language, at least at the five-year level. The expressive client learned the concepts receptively, even though she was not required to use nonverbal responses. She, thus, had a receptive knowledge of the concepts. Conclusions cannot be drawn, however, since results were obtained from only two subjects.

It was reported above that the receptively responding client verbally expressed all six concepts at the conclusion of the intervention period, as well as two weeks later on post-test 2. Although she was only required to use nonverbal responses, she did verbalize a few of the concepts periodically during the program administration. This may well have produced a practice effect. Thus, even though client B had no training in verbally expressing the concepts, the clinician's verbal model seemed to produce enough stimulus for this client to verbalize the concepts occasionally throughout the program and at the conclusion of the project. This lends support to Winitz' (1973) finding that language training should begin with comprehension. In other words, 
reception precedes expression in language learning. Again, conclusions cannot be drawn since only one subject was studied utilizing this approach. 


\section{CHAPTER V}

\section{SUMMARY AND CLINICAL IMPLICATIONS}

\section{Summary}

The purpose of this project was to measure and compare the language concept growth of two clients who utilized different response modes; client A utilized the expressive mode and client B utilized the receptive mode.

Two female clients, aged 5.8 and 5.5, from middle socioeconomic, Caucasian, monolingual homes were chosen for this project. Both children displayed similar below age level language profiles according to selected language assessment tools. Six concepts missed by both clients on the Boehm Test of Basic Concepts, form A, were chosen for remediation. These concepts were "behind," "over," "center," "between," "after," and "side." Additionally, the concepts of "away from" and "second" were presented to client A only.

Client A was administered a concept program utilizing the expressive mode of responding, while client B was administered a concept program utilizing the receptive mode of responding. Each client was evaluated by comparing pre- and post-test changes in performance.

The questions posed and results obtained were:

1. Did both clients demonstrate the ability to verbalize concepts on the post-tests of the individualized programs?

Both clients demonstrated the ability to verbalize concepts on post- 
tests 1 and 2 .

2. Did client A learn more concepts in eighteen sessions than client $B$ as measured by the post-tests 1 and 2 of the individualized programs and the Boehm Test of Basic Concepts, form B?

In the eighteen sessions of intervention client A learned two more concepts in fewer mean number of trials than client B. Also maintenance appeared more successful for client A than client B as noted in posttest 2; however, client B appeared to learn two more concepts than client A on the Boehm Test of Basic Concepts, form B post-test.

3. Did both clients tend to learn each concept in a similar number of trials?

Each client learned each of her concepts in a different number of trials.

It was concluded that the expressive program appeared more efficient than the receptive program at the five-year level. However, this project involved only two subjects and general conclusions, therefore, cannot be drawn.

\section{Clinical and Research Implications}

According to the results of this project, at the five-year level, the expressive mode of responding appeared to exhibit faster concept learning and better maintenance than the receptive mode of responding. Clinically it would appear that time spent on receptive language skill building could be eliminated and replaced by expressive language skill building instead. Obviously, conclusive evidence cannot be drawn from only two female subjects. A study of this nature must be conducted on a larger number of children, both female and male, before specific 
conclusions can be drawn.

This specific study compared only language delayed children and, therefore, does not have implications for the educationally mentally retarded, trainable mentally retarded, learning disabled, or emotionally handicapped population. In other words, etiologies other than language delay need to be studied to provide definitive conclusions.

For purposes of developmental norming, it also would be interesting to study the normal language developing population. Concepts acquired by older children might be administered to younger children in programs such as the ones in this project to determine their rate and mastery of concept acquisition.

Clinical research studies such as those suggested above would provide multidimensional results and more conclusive evidence in this still controversial area of language acquisition development and rate in relation to responding modes in the clinical setting. 


\section{SELECTED BIBLIOGRAPHY}

BLOOM, L., Talking, understanding, and thinking. In R. Schiefelbusch and L. Lloyd (Eds.), Language Perspectives: Acquisition, Retardation and Intervention. Baltimore: University Press (1974).

BLUMENTHAL, A. L., Language and Psychology: Historical Aspects of Psycholinguistics. New York: Wiley (1970).

BOEHM, A., The Boehm Test of Basic Concepts. New York: Psych. Corp. $(1967)$.

CARROLL, J., Words, meanings and concepts. In L. Jakobovits and M. Miron (Eds.), Readings in the Psychology of Language. New Jersey: Prentice Hall (1967).

CHOMSKY, N., Aspects of the Theory of Syntax. Cambridge, Mass.: MIT Press (1965).

CLARK, E. V., What's in a work? On the child's acquisition of semantics in his first language. In T. T. Moore (Ed.), Cognition Development and the Acquisition of Language. New York: Academic Press (1973).

CLARK, E..V., Some aspect of the conceptual basis for first language acquisition. In R. Schiefelbusch and L. Lloyd (Eds.), Language Perspectives: Acquisition, Retardation, and Intervention. Baltimore: University Press (1974).

COLLINS, P., and CUNNINGHAM, G., Writing Individualized Programs: A Workbook for Speech Pathologists. Portland, Or.: C. C. Publications (1976).

DONALDSON, M., and WALES, R. J., On the acquisition of some relational terms. In J. R. Hayes (Ed.), Cognition and the Development of Language. New York: Wiley $(1970)$.

DUNN, L. M., Peabody Picture Vocabulary Test. Circle Pines, Minn.: American Guidance Service (1965).

DUNN, L. M., and SMITH, J. 0., Peabody Language Development Kit. Nashville, Tenn.: American Guidance Service, Inc. (1966).

ENGELMANN, S., OSBORN, J., ENGELMANN, T., Distar Language I and II: An Instructional System. Chicago: Science Research Assoc. (1969). 
FRASER, C., BELLUGI, U., and BROWN, R., Control of grammar in imitation, comprehension, and production. Journal of Verbal Learning and Verbal Behavior, 2 (1969).

GRAHAM, F. K., BERMAN, P. W., and ERNHART, B., Development in preschool children of the ability to copy forms. Child Development, 36 (1965).

GRAY, B., and RYAN, B., Monterey Language Program. Monterey, Ca.: Monterey Learning Systems (1971).

GRAY, B., and RYAN, B., A Language Program for the Nonlanguage Child. Chicago: Research Press (1973).

GREENBERG, J. H., Language Universals. The Hague: Mouton (1966).

GUESS, D., A functional analysis of receptive language and productive speech: Acquisition of the plural morpheme. Journal of Applied Behavior Analysis, 2 (1969).

HOPPER, R., and NAREMORE, R., Children's Speech: A Practical Introduction to Communication Development. New York: Harper and Row (1973).

INGRAM, D., The relationship between comprehension and production. In R. Schiefelbusch and L. Lloyd (Eds.), Language Perspective: Acquisition, Retardation and Intervention. Baltimore: University Park Press (1974).

KLATZKY, R. L., CLARK, E. V., and MACKEN, M., Asymmetries in the acquisition of polar adjectives: Linguistic or conceptual. Journal of Experimental Child Psychology, 16 (1973).

LENNEBERG, E. H., and LENNEBERG, E., Foundations of Language Development. New York: Academic Press (1975).

MACCOBY, E. E., and BEE, H. L., Some speculations concerning the lag between perceiving and performing. Child Development, 36 (1965).

McNEILL, D., Production and perception: The view from language. Ontario Journal of Educational Research, 10 (3) (1968).

McNEILL, D., The Acquisition of Language: The Study of Developmental Psycholinguistics. New York: Harper and Row (1970).

MANDLER, G., Verbal learning. In T. M. Newcomb (Ed.), New Directions in Psychology. New York: Holt, Rinehart, and Winston (1967).

MECHAM, JEX, and JONES, The Utah Language Development Test. Salt Lake City: Woodruff Printing and Litho. (1969). 
OLSON, D. R., Cognitive Development: The Child's Acquisition of Diagnality. New York: Academic Press (1970).

PALERMO, E. S., More about less: A study of language comprehension. Journal of Verbal Learning and Verbal Behavior, 13 (1973).

PIAGET, J., and INHELDER, B., The Child's Conception of Space. London: Routledge and Kegan Paul (1965).

SLOBIN, D. I., Cognitive pre-requisites for the development of grammar. In C. A. Ferguson and D. I. Slobin (Eds.), Studies of Child Language Development. New York: Holt, Rineholt, and Winston (1973).

STARK, J., Current clinical practices in language. ASHA, 13 (1971).

WINITZ, H., Problem solving and the delaying of speech and strategies in the teaching of language. ASHA, 15 (1973). 


\section{APPENDIX A \\ COLLINS AND CUNNINGHAM'S (1976) 7 STEPS TO WRITING INDIVIDUALIZED PROGRAMS}

Step 1: Select the target behavior.
a. Use appropriate diagnostic tools to identify client's deficits.
b. Based on diagnostic information, decide what specific behaviors client needs to learn.
c. Select one of these behaviors as the target.

Step 2: Write a terminal objective.
a. What do you want the client to do?
b. Under what conditions do you want him to do it?
c. How well do you want him to do it?

Step 3: Write the Pre-test and the Post-test.
a. Identify the stimulus.
b. Identify the response.
c. Identify the level of acceptable performance.

ADMINISTER THE PRE-TEST

Step 4: Write a Task Sequence.
a. Identify the series of steps, beginning with the most simple and proceeding to the more complex for
1. Nonverbal responses.
2. Verbal responses.

Step 5: Do a Task Analysis. a. Identify the behaviors required to perform each task in
the task sequence.

Step 6: Incorporate the Task Sequence into the Delivery System.

a. This teaching strategy design must include: 
1. A clearly specified stimulus.

2. A cue.

3. A clearly defined response.

4. A schedule of reinforcement.

5. Criterion for movement.

Step 7: Provide for Tracking and Data Collection.
a. Correct response: /
b. Correct response which is reinforced: $X$
c. Incorrect response: 0

ADMINISTER THE PROGRAM

ADMINISTER THE POST-TEST 
BOEHM TEST OF BASIC CONCEPTS, FORM A

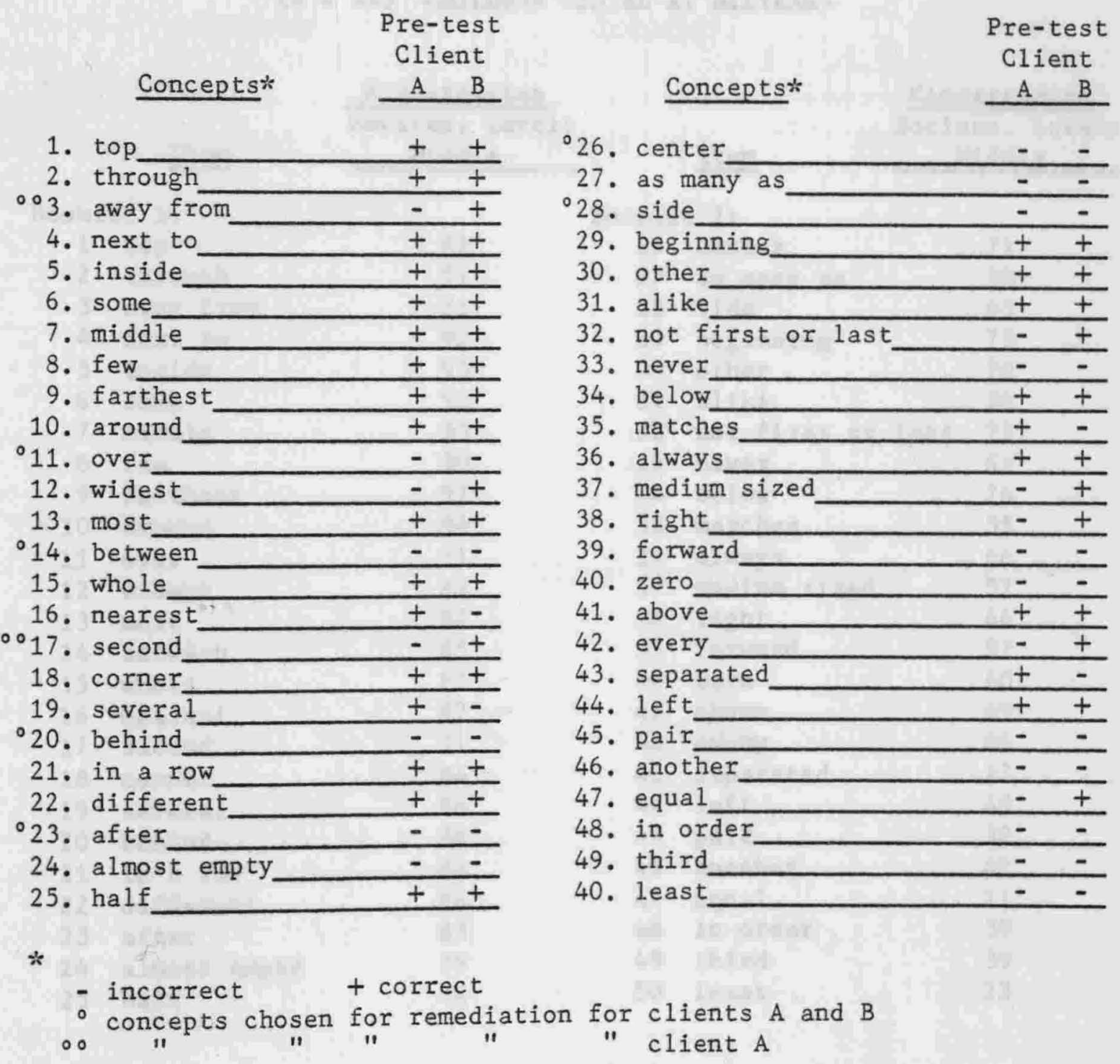




\section{APPENDIX C}

PERCENT PASSING EACH ITEM OF BOEHM TEST OF BASIC CONCEPTS, FORM A, BY GRADE AND SOCIOECONOMIC LEVEL (BOEHM, 1967) $(\mathrm{N}=453$ CHILDREN TESTED AT MIDYEAR $)$

\begin{tabular}{|c|c|c|c|c|c|c|c|}
\hline & Item & $\begin{array}{l}\frac{\text { Kindergarten }}{\text { Socioec. Level }} \\
\text { Middle }\end{array}$ & $1:$ & & Item & $\begin{array}{r}\text { Kind } \\
\text { Socio } \\
\mathrm{M} \\
\end{array}$ & $\begin{array}{l}\frac{\text { ergarten }}{\text { ec. Level: }} \\
\text { iddle }\end{array}$ \\
\hline $\mathrm{ok}$ & et 1: & & Bool & $\mathrm{klet}$ & t 2: & & \\
\hline 1 & top & 82 & & 26 & center & & 71 \\
\hline 2 & through & 91 & & 27 & as many as & & 58 \\
\hline 3 & away from & 81 & & 28 & side & & 65 \\
\hline 4 & next to & 92 & & 29 & beginning & & 73 \\
\hline 5 & inside & 93 & & 30 & other & & 70 \\
\hline 6 & some & 91 & & 31 & alike & & 56 \\
\hline 7 & middle & 93 & & 32 & not first or & last & 72 \\
\hline 8 & few & 90 & & 33 & never & & 61 \\
\hline 9 & farthest & 92 & & 34 & below & & 76 \\
\hline 10 & around & 94 & & 35 & matches & & 55 \\
\hline 11 & over & 91 & & 36 & always & & 66 \\
\hline 12 & widest & 83 & $y=1$ & 37 & medium sized & & 52 \\
\hline 13 & most & 92 & & 38 & right & & 46 \\
\hline 14 & between & 85 & & 39 & forward & & 57 \\
\hline 15 & whole & 82 & & 40 & zero & & 40 \\
\hline 16 & nearest & 97 & & 41 & above & & 69 \\
\hline 17 & second & 71 & & 42 & every & & 86 \\
\hline 18 & corner & 84 & & 43 & separated & & 47 \\
\hline 19 & several & 86 & & 44 & left & & 49 \\
\hline 20 & behind & 88 & & 45 & pair & & 32 \\
\hline 21 & in a row & 84 & & 46 & another & & 42 \\
\hline 22 & different & 86 & & 47 & equal & & 11 \\
\hline 23 & after & 83 & & 48 & in order & & 39 \\
\hline 24 & almost empty & 79 & & 49 & third & & 39 \\
\hline 25 & half & 78 & & 50 & least & & 22 \\
\hline
\end{tabular}


APPENDIX D

INDIVIDUALIZED PRE- AND POST-TESTS FOR CLIENTS A AND B

\section{$\underline{\text { Stimulus }}$}

\section{Expressive:}

Clinician asks:

"Where is the (object)?" $\underline{\text { Response }}$

Criteria

Receptive:

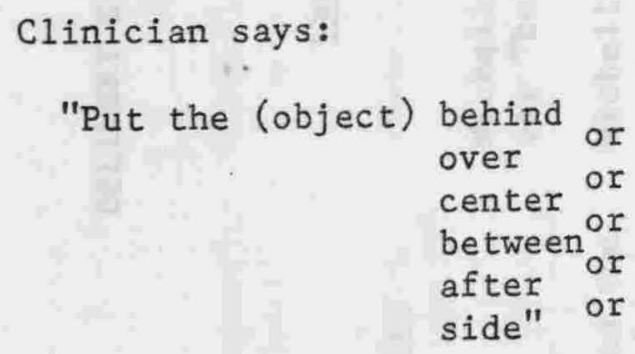

Client points to: Five trials each behind over center between after side

behind

over

center

away from

second

between

after

side

Five trials each

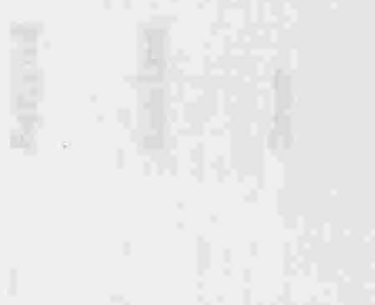


Present 10 objects in random order.

1. "The (object) is behind the (object)."

Michelle,

say "behind"

Behind

Michelle

2. "The (object) is/is not behind the (object). Is the (object) behind the (object)? Yes/no."

3. "The (object) is/is not behind the (object). Is the (object) behind the (object?"

4. "The (object) is behind the (object). Where is the (object)? behind"

5. "The (object) is behind the (object). Where is the (object)?"

6. "Where is the (object)?"

7. "The (object) is over the (object)." Michelle, say "behind"
Michelle

Michelle

Michelle

ithen $15=$

Michelle

Behind

Over
Behind

Yes/no

Yes/no

Behind

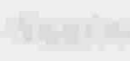

Reinforce-

ment

Schedule

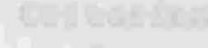

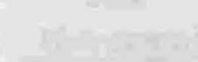

Criterion

for

Movement

$100 \%$ good

$100 \%$ token

$100 \%$ good

$50 \%$ token

10 consec.

$50 \%$ good

$50 \%$ token 10 consec.

$50 \%$ good

$50 \%$ token

20 consec.

$50 \%$ good

$10 \%$ token

$10 \%$ good

$10 \%$ token

$100 \%$ good

$100 \%$ token
20 consec.

20 consec.

10 consec. 


\section{$\underline{\text { Stimulus }}$}

8. "The (object) is over the (object). Michelle Is the (object) over the (object)? Yes/no."

9. "The (object) is over the (object). Is the (object) over the (object)?"

10. "The (object) is over the (object). Where is the (object)? Over"

11. "The (object) is over/behind the (object). Where is the (object)?"

12. "Where is the (object)?"

13. "The (object) is in the center of the (shape)."

14. "The (object) is/is not in the center of the (shape). Is the (object) in the center of the (shape)? Yes/no."

15. "The (object) is/is not in the center of the (shape). Is the (object) in the center?"

16. "The (object) is in the center of the (shape). Where is the (object)? Center."
Reinforce-

Michelle

Michelle

Michelle

Michelle

Michelle

Michelle, say "center"

Michelle

Michelle

Michelle
Yes/no

Over

Over/behind

Over/behind

Center

Yes/no

$50 \%$ good

$50 \%$ token

$50 \%$ good

$50 \%$ token

$50 \%$ good

10 token

$10 \%$ good

$10 \%$ token

$100 \%$ good $100 \%$ token

$100 \%$ good

$50 \%$ good

$50 \%$ token

Center

Yes/no

$50 \%$ good $50 \%$ token ment

Schedule

$100 \%$ good

$50 \%$ token

Response

Yes/no

Criterion

for

Movement

10 consec.

10 consec.

20 consec.

20 consec.

20 consec.

10 consec.

10 consec.

$50 \%$ token 


\section{Stimulus}

17. "The (object) is in the center, behind, or over. Where is the (object)?"

18. "Where is the (object)?"

19. "The (object) is away from the (object)."

20. "The (object) is/is not away from the (object). Is the (object) away from the (object)? Yes/no."

21. "The (object) is/is not away from the (object). Is the (object) away from the (object)?"

22. "The (object) is away from the (object). Where is the (object)? Away from."

23. "The (object) is away from, behind, over, center of the (object).

Where is the (object)?"

24. "Where is the (object)?" $\underline{\text { Cue }}$

Michelle

Michelle

Michelle, say

"away from"

Michelle

Michelle

Michelle

Michelle

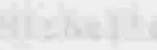

Michelle
Reinforce-

behind,

over

Center, behind,

over

Away from

Yes/no

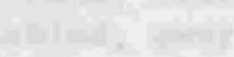

Yes/no

Away from

Away from, behind,

over,

center

Away from,

behind,

over, center
$10 \%$ good

$10 \%$ token ment

Schedule

$50 \%$ good

$10 \%$ token

\section{Criterion}

for

Movement

20 consec.

$10 \%$ good

$10 \%$ token

20 consec.

$100 \%$ good 10 consec.

$100 \%$ token

$100 \%$ good

$50 \%$ token

10 consec.

$50 \%$ good

$50 \%$ token

10 consec.

$50 \%$ good

$50 \%$ token

20 consec.

$50 \%$ good

$10 \%$ token

20 consec. 


\section{Stimulus}

25. "The (object) is second."

26. "The (object) is/is not second. Is the (object) second? Yes/no."

27. "The (object) is/is not second. Is the (object) second?"

28. "The (object) is second. Where is Michelle the (object)? Second."

29. "The (object) is second/behind/over/ Michelle center/away from. Where is the (object)?"

30. "Where is the (object)?"

31. "The (object) is between."

32. "The (object) is/is not between. Is the (object) between? Yes/no."

33. "The (object) is/is not between. Is the (object) between?"

34. "The (object) is between. Where is the (object)? Between."
Michelle

\section{Cue \\ Michelle, \\ Michelle \\ Michelle} say "second"

Miche1le
Reinforce-

ment

Schedule

$100 \%$ good $100 \%$ token

Yes/no

Yes/no

Second

$100 \%$ good $50 \%$ token

$50 \%$ good

$50 \%$ token

$50 \%$ good

$50 \%$ token

$50 \%$ good

$10 \%$ token

$10 \%$ good

$10 \%$ token

Between

$100 \%$ good $100 \%$ token

Yes/no

$100 \%$ good $50 \%$ token

Yes/no

$50 \%$ good

$50 \%$ token

Between

$50 \%$ good

$50 \%$ token
Criterion for

Movement

10 consec.

10 consec.

20 consec.

20 consec.

20 consec.

20 consec.

20 consec.

20 consec.

20 consec.

20 consec. 


\section{Stimulus}

35. "The (object) is between/over/ behind/center/away from. Where is the (object)?"

36. "Where is the (object)?"

37. "The (object) is after the (object)."

38. "The (object) is/is not after the (object). Is the (object) after the (object)? Yes/no."

39. "The (object) is/is not after the (object). Is the (object) after the (object)?"

40. "The (object) is after the (object). Michelle Where is the (object)? After."

41. "The (object) is after/behind/ second/over/between/away from/ center. Where is the (object)?"

42. "Where is the (object)?"

\section{Cue}

Michelle

Michelle

Michelle, say

"after"

Michelle

Michelle

Michelle
Reinforce-

ment

Response

Second/behind/

between/over/

away from/center

Schedule

$50 \%$ good

$10 \%$ token

$10 \%$ good

$10 \%$ token

After

$100 \%$ good $100 \%$ token

Yes/no

$100 \%$ good

$50 \%$ token

20 consec.

Yes/no

$50 \%$ good

$50 \%$ token

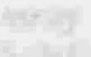

After

After/between/ over/behind/ away from/center/second

\section{Criterion}

for

Movement

20 consec.

20 consec.

20 consec.

11
$50 \%$ good 20 consec.

$50 \%$ token

$50 \%$ good

$10 \%$ token

20 consec.
$10 \%$ good

$10 \%$ token
20 consec. 


\section{Stimulus}

43. "The (object) is at the side of the shape."

44. "The (object) is at the side of the shape. Is the (object) at the side? Yes/no."

45. "The (object) is/is not at the side of the shape. Is the (object) at the side?"

46. "The (object) is at the side of the shape. Where is the (object)?

Side."

47. "The (object) is at the side/ center/after/between/behind/away

from/second. Where is the object?"

48. "Where is the (object)?"

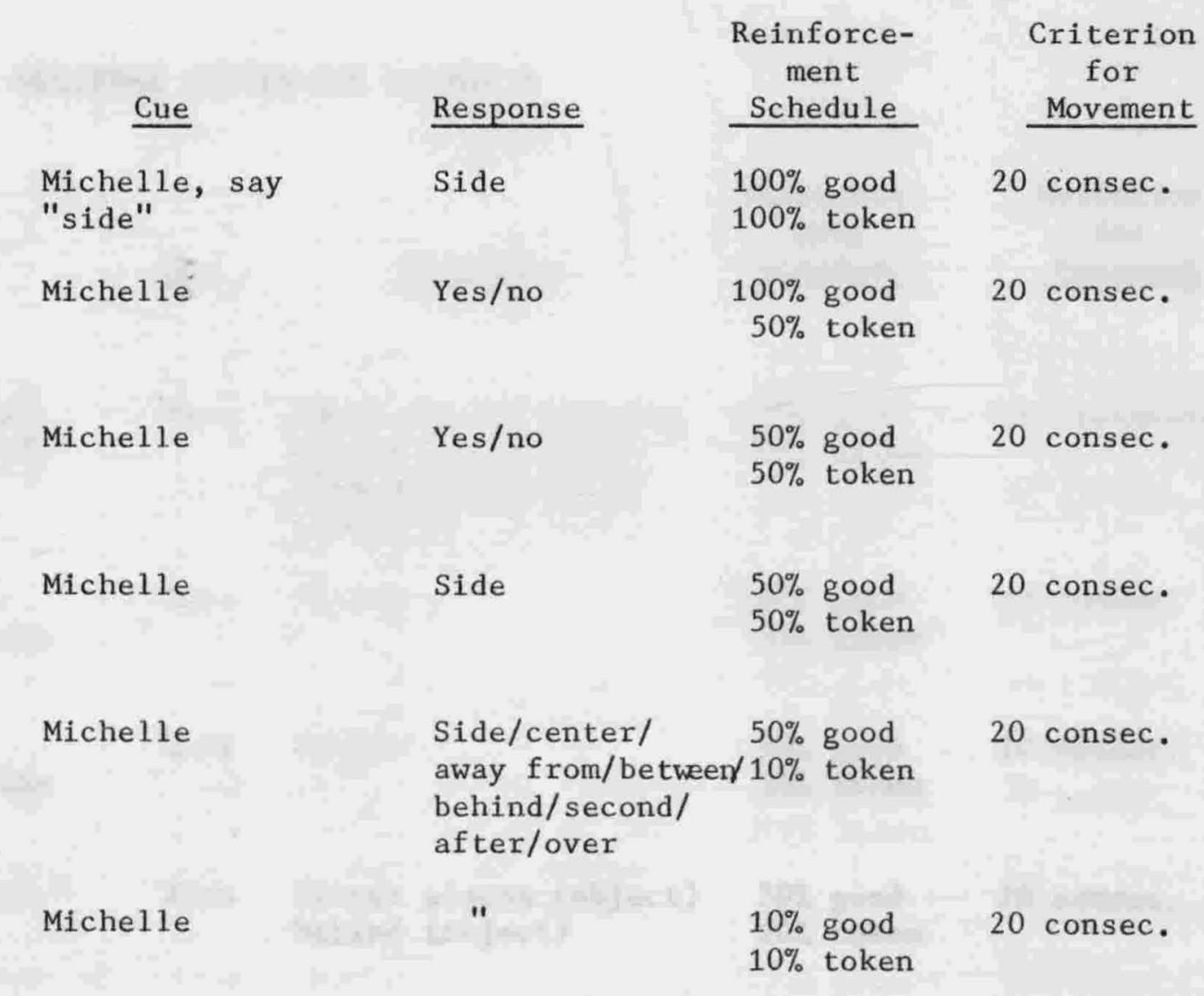




\section{DELIVERY SYSTEM FOR CLIENT B}

\section{Stimulus}

Present 10 objects in random order.

1. "The (object) is behind the (object). Put the (object) behind the (object)."

2. "The (object) is/is not behind the (object). Is the (object) behind the (object)? Yes/no."

3. "The (object) is/is not behind the (object). Is the (object) behind the (object)?"

4. "The (object) is behind the (object)." Remove and mix objects. "Put the (object) behind the (object)."

5. "Put the (object) behind the (object)."

6. "The (object) is over the (object). Put the (object) over the (object)."

\begin{tabular}{cl} 
Cue & \multicolumn{1}{c}{ Response } \\
Tara & $\begin{array}{l}\text { Client places (object) } \\
\text { behind the (object) } \\
\text { when manipulated by } \\
\text { clinician }\end{array}$ \\
Tara Yes/no & $\begin{array}{l}\text { Yes/no } \\
\text { Tara }\end{array}$ \\
Tara & $\begin{array}{l}\text { Client places (object) } \\
\text { behind (object) }\end{array}$
\end{tabular}

Tara

Tara

Client places (object) over the (object) when manipulated by clin.

\section{Reinforce- \\ ment \\ Schedule \\ Criterion \\ for \\ Movement}

$100 \%$ good

$100 \%$ token

10 consecutive

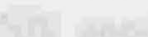

$100 \%$ good

$50 \%$ token

$50 \%$ good

$50 \%$ token

$50 \%$ good

$10 \%$ token

20 consec.

$10 \%$ good

$10 \%$ token

20 consec.

$100 \%$ good $100 \%$ token
10 consec. 


\section{$\underline{\text { Stimulus }}$}

7. "The (object) is/is not over the (object). Is the (object) over the (object)? Yes/no."

8. "The (object) is/is not over the (object). Is the (object) over the (object)?"

9. "The (object) is over/behind the (object)." Remove and mix objects. "Put the (object) over/behind the (object)."

10. "Put the (object) over/behind the (object)."

11. "The (object) is in the center of the (shape). Put the (object) in the center of the (shape)."

12. "The (object) is/is not in the center of the (shape). Is the (object) in the center of the (shape)? Yes/no."

13. "The (object) is/is not in the center of the (shape). Is the (object) in the center of the (shape)?"
Reinforce-

Tara Yes/no

Tara

Client places object over/behind (object).

Tara

Client places (object) over/behind (object).

Tara

Client places (object) in the center of the

(shape) when manipulated by clinician.

Tara Yes/no

Yes/no

Tara

Yes/no ment

Schedule

$100 \%$ good

$50 \%$ token

Criterion

for

Movement

20 consec.

$50 \%$ good

20 consec.

$50 \%$ token

$50 \%$ good

$10 \%$ token

20 consec.

$10 \%$ good

$10 \%$ token

20 consec.

$100 \%$ good $100 \%$ token

10 consec.

(10)

$100 \%$ good

$50 \%$ token

20 consec.

$50 \%$ good

20 consec. 


\section{Stimulus}

14. "The (object) is in the center, behind, over." Remove and mix objects. "Put the (object) in the center, behind, over."

15. "Put the (object) over, behind, in the center."

16. "The (object) is between. Put the (object) between."

17. "The (object) is/is not between. Is the (object) between? Yes/no."

18. "The (object) is between. Is the (object) between?"

19. "The (object) is between/over/behind/ center." Remove and mix objects. "Put the (object) in the center/over/ behind/between."

20. "Put the (object) over/behind/between/ center."

21. "The (object) is after the (object). Put the (object) after the (object)."
Cue

Tara

(1)

Tara

Tara

Tara Yes/no

Tara

Tara

Tara

Tara
Client places (object)
between when manipulated by clinician

Client places (object) in the center, over, behind

II

Yes/no

Client places (object) over/between/behind/ center

"

C1ient places (object) after (object) when manipulated by clinician
Reinforce-

ment

Schedule

$50 \%$ good

$10 \%$ token

20 consec.

$10 \%$ good

$10 \%$ token

$100 \%$ good

$100 \%$ token

10 consec.

$100 \%$ good

$50 \%$ token

$50 \%$ good

$50 \%$ token

$50 \%$ good

$10 \%$ token

wan? as a

$10 \%$ good

$10 \%$ token

$100 \%$ good $100 \%$ token
20 consec.

20 consec.

20 consec.

(1)

(1)

20 consec.

10 consec. 


\section{Stimulus}

22. "The (object) is/is not after the (object). Is the (object) after? Yes/no."

23. "The (object) is/is not after the (object). Is the (object) after?"

24. "The (object) is after/between/behind/ center/over the (object). Put the (object) after/between/behind/center/ over the (object)."

25. "Put the (object) over/between/behind/ center/after the (object)."

26. "The (object) is at the side of the shape. Put the (object) at the side of the shape."

27. "The (object) is at the side of the shape. Is the (object) at the side? Yes/no."

28. "The (object) is/is not at the side of the shape. Is the (object) at the side?"

29. "The (object) is after/between/behind/ center/over/side of (object) or shape. Put the (object) after/between/behind/ center/over/side of (object) or shape."

\section{$\underline{\text { Cue }}$}

Tara

Yes/no

Tara

Yes/no

Tara

Client places (object) over/after/between/

behind/center

Tara

Tara

Client places (object) at side of shape when manipulated by clin.

Tara

Yes/no

Yes/no

Tara

Client places (object) over/side/behind/between/center/after

\section{Reinforce-}

ment

Schedule

$100 \%$ good

$50 \%$ token

$50 \%$ good

$50 \%$ token

$50 \%$ good

$10 \%$ token

$10 \%$ good

$10 \%$ token

$100 \%$ good

$100 \%$ token

$100 \%$ good

$50 \%$ token

$50 \%$ good

$50 \%$ token

$50 \%$ good

$10 \%$ token
20 consec.

20 consec.

20 consec.

Criterion

for

Movement

20 consec.

20 consec.

20 consec.

20 consec.

20 consec. 
Appendix F (Cont.)

\section{Stimulus}

30. "Put the (object) over/center/behind/ between/after/side, of shape or (object)."
Reinforce-

ment

Schedule

$10 \%$ good

$10 \%$ token
Criterion

for

Movement

Tara Client places (object) over/side/behind/between/center/after 


\section{APPENDIX $G$}

\section{BOEHM TEST OF BASIC CONCEPTS}

Pre-test: Form A

Post-test: Form B

Client A

\section{Concepts*}

1. top

2. through

3. away from

4. next to

5. inside

6. some

7. middle

8. few

9. farthest

10. around

11. over

12. widest

13. most

14. between

15. whole

16. nearest

17. second

18. corner

19. several

20. behind

21. in a row

22. different

23. after

24. almost empty

25. half

26. center

27 . as many as

28. side

29. beginning

30. other

31. alike

32. not first or last

33. never

34. below

35. matches

36 . always
Pre- Post-

$\frac{t}{+}+$

$-\quad+$

$\begin{array}{ll}+ & t \\ + & +\end{array}$

$+\quad+$

$+$

$+$

$+$

$-\quad+$

$-\quad-$

$+$

$-\quad+$

$+\quad+$

$+\quad+$

$-\quad+$

$+$

$+$

$+$

$+$

$+\quad-$

$+$

$-$

$-+$

$+\quad-$

$-\quad+$

$-\quad+$

$-\quad+$

$+\quad+$

$+\quad+$

$+$

\begin{tabular}{cc}
- & - \\
- & - \\
\hline+ & + \\
+ & + \\
\hline+ & + \\
\hline
\end{tabular}

$+\quad+$
Client B

Pre- Post-

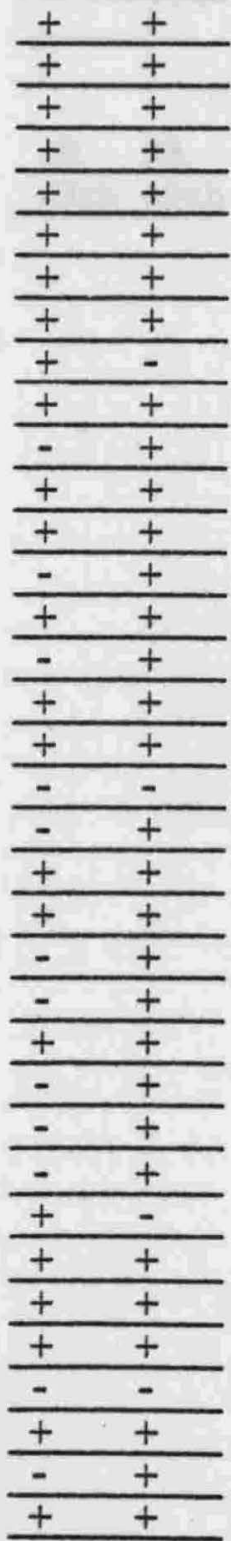




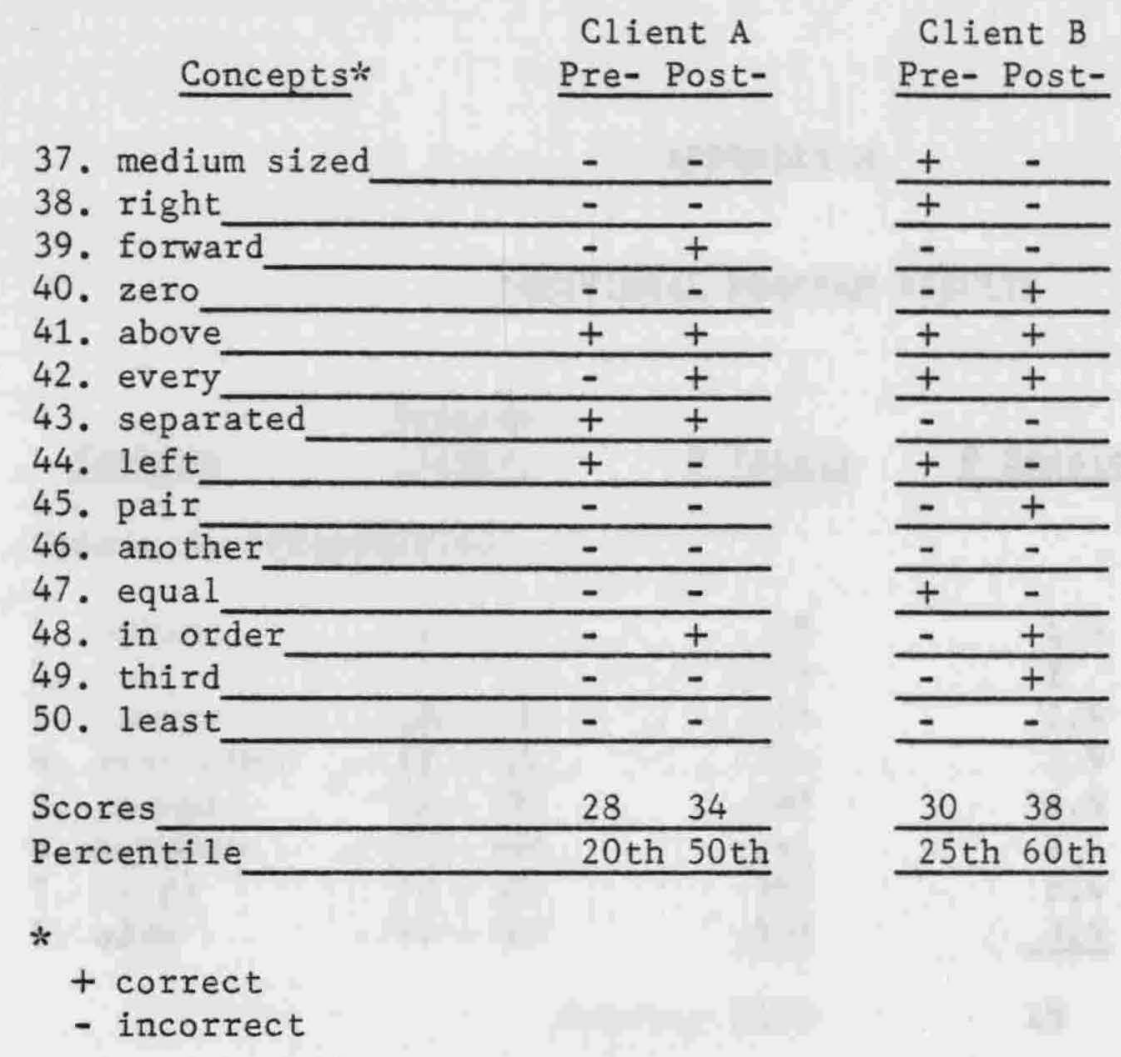




\section{APPENDIX $\mathrm{H}$}

INDIVIDUAL PROGRAM RESULTS

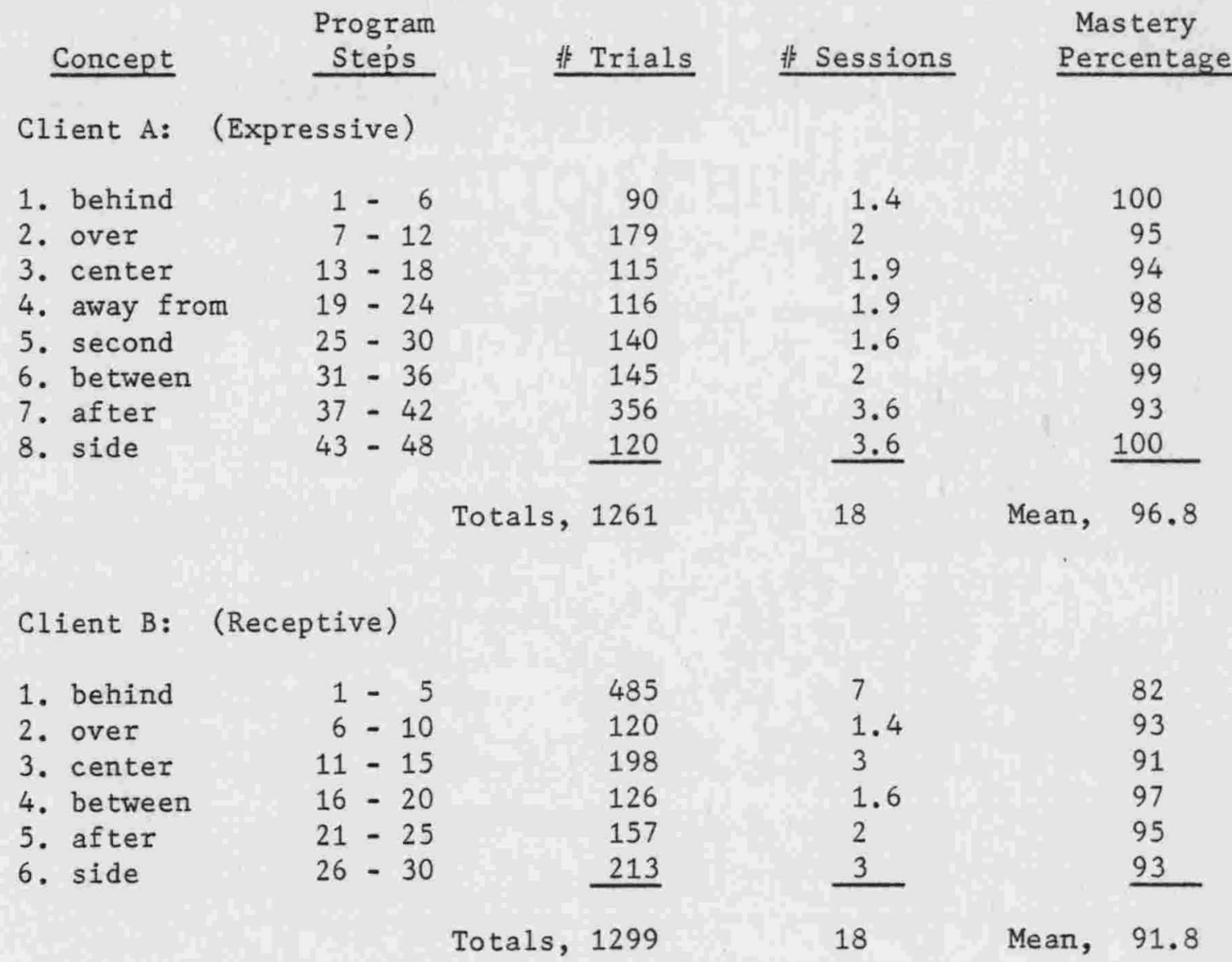

